\title{
Coal-Mining Industry as a Forming Factor of Social, Cultural, and Linguistic Environment of Kuzbass as Resource Region of Siberia
}

\author{
Dmitryi Kuznetsov ${ }^{1}$, Nadezda Rabkina ${ }^{1,}{ }^{*}$, Marina Ryabova ${ }^{1}$, and Olga Valko ${ }^{1}$ \\ ${ }^{1}$ Kemerovo State University, 650000, 6 Krasnaya St., Kemerovo, Russia
}

\begin{abstract}
The coal-mining industry ensures its sustainable development by forming the complex regional environment, embracing urban, social, cultural, linguistic, and academic components. The environment eventually exerts itself in a number of outcomes. It makes up a multiform regional cogniosphere (i.e. noosphere, ideosphere, logosphere, semiosphere, conceptosphere) responsible for increasing the regional population's awareness of the coal mining specifics, as well as forms positive attitudes to the mining sector of economy and mining professions, and finally forges the regional identity. The environment is responsible for increasing the popularity of professional coal-mining education which enables the stability and survivability of the mining professions and efficient personnel change in due time. The environment affects adjacent economic spheres (tourism, service, recreation, production, etc.) so as they can make use of the regional specific features and diversify their products and services. Thus, the coal-mining industry and the above mentioned environment form a closed-cycle system whose constituents affect each other mutually and ensure efficient coexistence and development. The cultural, linguistic, and urban environment of the region can be viewed as additional means of supporting and promoting sustainable development of the regional economy and culture through its manipulative potential.
\end{abstract}

\section{Introduction}

There are currently more than 50 coal mines and 36 open pit mines in Kuzbass, which supply more than half of all Russian coal and almost $100 \%$ of Russian coking coal. Media often depict Kemerovo as the mining capital of Russia. As a result, Kuzbass abounds in material and not-material objects related to its main industry.

As a staple industry of the region, the coal-mining sector strives to resolve the issues of sustainable development to achieve economic stability and social welfare for Kuzbass. The dangers stem not only from the exhaustible and nonrecoverable nature of coal deposits but also from the ecological threats coal mining entails $[1,2]$. One of the most recent cases was the so called black snow, which made headlines of foreign media. The media hype

\footnotetext{
${ }^{*}$ Corresponding author: nrabkina@mail.ru
} 
triggered a chain of rather unpleasant associations with Kuzbass by exploiting words with negative connotation (strange, eerie, toxic, disturbing, horrifying, black, killer, toll, death, Apocalypse, etc.).

Moreover, Russian people's memory still keeps the image of the turbulent events of the 1990's when miners' strikes of 1989-1991 were the first public expressions of mass dissatisfaction. Indeed, the linguo-cultural project Word Associations Net puts "strike" on the second place on the list of verbal associations for "Kuzbass" [3]. Local people remember the period of political instability with nostalgia since it was the time when Kuzbass aspired to make a difference, if not change the course of domestic history. Kuzbass miners' impetus actually was something that rolled and shook the whole infrastructure of the Soviet Union, making further reforms possible.

The other side of the media image of Kuzbass is connected with gas explosions and cave-ins. It is no wonder that a coal region cannot claim total safety. Two disasters made headlines of domestic and foreign media: the Ulyanovskaya mine disaster, which took lives of 110 miners in 2007, and a double gas explosion at the Raspadskaya mine in 2010, which killed 91 people.

Alternatively, the positive image of the region features Kuzbass as one of Russia's most urbanized and industrialized areas. The negative stereotypes recede with the mass media covering the political and social aspects of life in Kuzbass. Sergey Tsivilyov, the governor of Kemerovskaya Oblast, is a proponent of the regional comprehensive project entitled The Strategy of a Social and Economic development of the Region until 2035. The programme outlines several top-priority directions, in particular, industrial modernization, ecology improvement, raising the standard of life, demographical growth, etc. In 2019 the slogan ("Clean coal - clean Kuzbass") was coined. The changes will take years to become noticeable, but are meant to inspire confidence in the economic prospects of Kuzbass.

Considered within the humanities framework, coal mining influences the language and culture of the region extensively, forming the multiform regional cogniosphere (i.e. noosphere, ideosphere, logosphere, semiosphere, conceptosphere) $[4,5]$. In its turn, the complex regional environment (urban, social, cultural, linguistic, and academic) serves an essential condition of the sustainable development of the coal-mining industry by raising awareness of the professional aspects, promoting the prestige of the professions concerned with it, and boosting the positive attitude towards the coal-mining sphere.

\section{Materials and methods}

The study started off with the hypothesis that the coal-mining sector directly and indirectly forms the complex sociocultural environment and regional community identity and benefits from them. Both the environment and identity unify regional population, sustain interest in the economic specialization of the region, and bring up the local youth respectful to the staple industry or ready for employment in it.

The sociocultural approach used in the article was interdisciplinary. It relied mainly on the conceptual explication and interpretation of heterogeneous cultural, social, linguistic, economic, and natural phenomena. The study included observing the regional environment with a view to selecting, collecting, and describing the evidence of coal-mining elements and attributes reflected or embedded in the natural and urban fabric, as well as cultural and linguistic patterns of the region. The interrelations and interdevelopment of the constituents in the regional environment were evidentiated by comparison, generalization, hypotheticodeductive processing, and system analysis of the data.

In the last few decades, similar studies became possible thanks to adoption of the category known in the humanities as the text of culture [6]. The term implies that any individual who is the subject of culture perceives and interprets events, actions, facts, 
artefacts, and others, thus producing the text of culture. The category helps reveal and describe the value and cultural significance of the objects, entities, phenomena, and cultural properties expressed in a semiotic form. Decoding and interpreting the text of culture within various frameworks enables explicating cultural, social, linguistic, and other trends, practices, traditions, customs, and ways. Though dynamic and constantly changing, the text of culture may still provide snapshots of collective cultural and social experience, values, concepts, and senses substantial for the specific space-time continuum. The text of culture represents the universal thesaurus of cultural and historic information. Thus, the category designated as the text of culture affords various renderings, ranging from the most comprehensive to the most focused.

The text of culture is studied through the analysis of its structure, contents, and mode of existence. The main areas for data collection included social, natural, urban, and cultural environment. The main objective was also to detect the instances of coal-mining penetration into the social, cultural, linguistic, and academic sphere.

\section{Results and Discussion}

\subsection{Social and sociocultural environment}

Historians, sociologists, and political experts are used to presenting coal miners as a distinct group of population. The shift to new sources of energy altered the perception of coal miners' communities, labelling them as a conservative part of the society trying hard to survive in a harsh economic competition with the high-tech industry and eventually doomed to disappear.

Derrick Price in his book Coal Cultures: Picturing Mining Landscapes and Communities defines a coal culture, first, as a place in the past, which is full of well-paid jobs, and, second, as a strong, independent, warm-hearted, friendly and supportive community with respect for family values.

In many developed countries, such communities are gradually slipping away, but it will take them a very long time to die. According to D. Price, the only promising future in the coal industry is to become part of the heritage movement. Sooner or later, its unique culture will be confined to local museums [7].

Slipping away or not, mining communities still matter a lot. Disregard for the American coal mining community cost Hillary Clinton her presidential elections. By failing to pay this hard-working blue-collar stratum of society enough respect, Clinton demonstrated that she had no respect for the working class America at large [8].

Price defines nostalgia as a major emotion in mining communities: it supports the community's spirit and communal memory [7]. Alternatively, S. E. Bell and R. York assess the coal community's economic identity negatively because of its manipulative potential [9]. The effects of this potential can be quite big as coal cultures are highly consolidated and influential owing to the regional identity. Even living in the coal region makes people associate themselves with the mining professions and the industrial process of the region. A good example of instilling this positive attitude can be obtained from the text of a patriotic song composed by O. Gazmanov, a famous Russian singer, after the toponym "Kuzbass" gained its official status in late 2018. The refrain exploits the US - THEM binary opposition, urging every single of the 2,694,877 region residents to see themselves as coal industry workers, whose number amounted to only 88,000 people in 2016 [10].

The song glorifies the mining profession by depicting miners as heroes descending into the entrails of the earth to extract the 'black gold', thus referring to chthonian mythology and symbolism. The heroic aspect is reinforced due to metaphorization of mining processes 
and featuring them as battles in which miners descend into the mine as if rushing to the attack. The figure of speech places the highest value on coal and displays it as an inalienable element of life for Kuzbass residents.

The administration of the region maintains the I-live-in-a-mining-region-hence-I-am-aminer attitude by organizing large-scale festivals and celebrations of the Coal Miner's Day (last Sunday of August). The preparation for the festival starts long before the event, accompanied by covering the process in the regional mass media, posting up huge billboards in the streets, carrying out educational and cultural activities. Every year the core of the celebration moves to a different mining center of the region thereby increasing its sweeping effect.

Summing up, coal cultures impose systems of values and perception modes, which are likely to not only unify the population, but also manipulate it.

\subsection{Natural and urban environment}

Coal mining shapes the outlooks of both natural and urban areas. For Kuzbass residents, the natural (non-urban) landscapes are divided mainly into pristine Siberian taiga and so called industrial areas. Quite frequently, the latter form the transition zone between the urban residential and natural non-residential areas.

The transitional status of industrial landscapes owes to the fact that mine dumps and open-pit mines are mostly located on the outskirts of cities and towns. Mine dumps, openpit mines, and black hills constitute the recognizable industrial landscape that Kuzbass strongly associates with and that is usually referred to as "moonscapes" or "lunar landscapes". Coined in the XX century, these euphemisms evidentiate the romantic approach mingled with the admiration of industrial might and hide the lack of hope rising from the analogy with the barren surface of the moon fated to remain so.

Coal mining has a long history in Kuzbass, and so does the history of disturbed land reclamation. As a rule, a typical reclaimed landscape features steep hills and craters with parallel lines of pine trees that are called posadky (plantings). The oldest plantings are half a century old and gradually merging with the natural taiga. Local people visit the "plantings" for barbecue and picnics or for gathering mushrooms and berries, seabuckthorn in particular. Planting sea-buckthorn is considered the best way to re-cultivate the "moon landscapes" [11], and gathering sea-buckthorn is viewed as a long-lived tradition sprung by coal mining. Reclaiming activities have become a part of life for many local communities, inspiring social integrity through stimulating volunteering initiatives.

The environment is traditionally perceived through the toponymic names. Very symptomatic is the fact that the names "Kemerovskaya oblast" and "Kuzbass" (Kuznetsk coal basin) have always been interchangeable in mass consciousness. However, they became official synonyms only in December 21, 2018.

The analysis of regional toponyms, urbonyms, and landmarks may result in the following classification: (1) urban areas with names derived from lexemes related to coal mining; (2) urban areas named after famous people, often of local importance, associated with coal mining; (3) historical buildings related to coal mining; (4) other landmarks including monuments and urban design elements, e.g. the fountain with three miners near the Philharmonic theatre, the bas-relief on the wall of the Polytechnic University, bus stops shaped as mining excavator scoops, and numerous memorials - from the grand sculpture designed by Ernst Neizvestny to various memorial plaques. A number of city institutions and businesses have coal-mining names, e.g. hotel Kuzbass, regional sport center Kuzbass, publishing house Kuzbass, etc. 
Describing the natural, urban, and industrial environments of Kuzbass, one inevitably comes to conclusion that they coexist inseparably not only in the real life, but also in the consciousness of Kuzbass residents.

\subsection{Cultural environment}

Though coal-mining museums are associated in the first place with natural science and geology of the region, they can also have historical potential and even offer experience of going down a closed mine or a mine replica [7]. Opened in 1999, the Museum of Coal and Coal Chemistry of the Siberian Branch of the Russian Academy of Sciences remains one of its kind in Russia. It hosts large collections of coal and tells the story of coal mining in Kuzbass.

Another unique coal-mining museum is Krasnaya Gorka (Red Hill). Since its foundation in 1991, this open-air museum was meant specially for preserving mining history. Now it is the only urban museum cluster in Kemerovo. It includes the historical landscapes on the right bank of Kemerovo centre. Krasnaya Gorka is the only museum in the region with a replica of real mining environment and a display of authentic mining machines.

The museum originally started as a research centre specializing in the history of the Autonomous Industrial Colony Kuzbass. The colony was an unprecedented project set up by V. I. Lenin and several prominent socialists from the USA and the Netherlands. In 19211927, over 600 specialists in coal mining and chemical industry came to share their experience with local workers and restore the ruined industry.

Gradually, Krasnaya Gorka has turned into a museum of Kuzbass industry. The vast archives of the museum spark numerous scientific projects on the past of local coal mining and its connections with the history of Russia. The museum maintains contacts with foreign cultural and historical organizations promoting the Kuzbass brand abroad. The Dutch architectural heritage in the region resulted in a series of joint projects with architectural organizations and educational institutions of the Netherlands.

Local museums benefit from coal-mining industry as coal mining is a source of enlarging museum funds and diversifying museum collections. The museum of local lore demonstrates a number of exhibits donated by local mines and open pits, such as petrified prehistoric flora and fauna, or curiosities like a UFO-shaped clay-stone disk.

So far, the region has accumulated over 30 historical mine-related sites that are scattered all over Kuzbass, not to mention memorial plaques.

The system of museums, monuments, and historical sites pervades the region, serving the historical bridge between the past and the present of coal-mining region and constructing the historical background for the regional population.

Regional art revolves to some extent around coal mining, gaining inspiration from it. Experts of Kemerovo regional museum of art describe the regional art as a specific trend of their funds endowing the museum with individuality. The main motifs presented in works of art are mostly twofold, either representing coal mining as a dynamic system and an engine for progress, or heroizing the people of mining profession.

In 2016, Krasnaya Gorka hosted an exhibition of coal sculptures by self-taught Kuzbass artist Igor Suvorov, whose works are purchased by Russian and foreign collectors. Coal is very fragile and hard to process, which makes sculptures from it rather expensive [12].

It is a mistaken belief that Kuzbass is potrayed only in works of regional artists. In 2008 Kemerovo museum of Art welcomed an exhibition of Dutch industrial paintings called "The Landscapes of Holland". Five Dutch artists visited the Shchernigovets open-pit mine and had a plain-air session [13]. 
The city sculpture reflects historical and heroic motives of coal mining (Mikhailo Volkov's monument, In Memory of Kuzbass Coal Miners by Ernest Neizvestny, the celebrated musical fountain in front of the Kemerovo Philharmonic Hall unites three coal miners as three chronologically arranged images, etc.).

The museum cluster of Krasnaya Gorka includes a monument called Horse Driver, commemorating all the mining horses that died underground. In Kiselyovsk there is a monument called Baby-Miner that depicts a small boy dressed as a miner and renders the idea of continuity of family traditions.

Coal-mining affects the art component of the regional environment as a source of inspiration and individualization, making it a vehicle of heroic ideology and hence a means of manipulation.

Russian educational standards stipulate the regional component in curricula of secondary and tertiary education. It mostly concerns humanities as subjects and programs may engage historical and cultural facts about the region; however, information about geography and science (e.g. chemical processes and reactions specific of fossil fuels such as coal carbonization) may be also studied in gaining popularity STEM education. The curricular and extracurricular activities at schools involve field trips to the local museums and historical sites, which offer a range of guided tours, quests, workshops, as well as specialized literature on various topics. Thus, by turning the city history into quests and games, the museum shows its relevance and hereditary character.

Museums serve fieldwork sites with a huge educational potential and become part of vocational training [14], especially for geologists and architects from the Polytechnic University as well as interpreters of Kemerovo State University and tour guides from the University of Culture and Arts. Dutch heritage in Kuzbass regularly attracts students of architecture from Delft promoting international academic contacts.

Literary component is considerable. The Union of Kuzbass writers has over 60 members and dozens of literary groups. Leslie Urion, an English poet, visited Kuzbass in 2013 and entitled his poetic effort "Wombat Goes Walkabout" featuring the naughty wombat and yetis' adventures in Kuzbass. The history of the Autonomous Industrial Colony inspired a number of foreign authors. Comrade One-Crutch was written by former colonist, feminist and devoted socialist Ruth Kennell. It was translated into Russian and successfully adapted for stage in 2012. Kennell's life still fascinates modern historians. In 2017 American professor of American Studies Julia Mickenberg dedicated to her a chapter in her monograph "American Girls in Red Russia: Chasing the Soviet Dream" $[15 ; 16]$. It's not the first time Kuzbass sparks scientific and literary interest.

Language and literature definitely make the biggest impact on the regional cogniosphere because of emotional and value constituents.

Kuzbass has about ten chapels built to commemorate deceased miners, four of which featuring St. Varvara (Barbara) in Kemerovo, Kiselyovsk, Mezhdurechensk, and Novokuznetsk. St. Varvara is a Christian martyr and the saint patron of miners. A large statue of St. Varvara in Russian Orthodox Church style is on the territory of Krasnaya Gorka. In October 2018, Sergey Tsivilyov promised to set up St. Varvara's statue next to the Kuzbass sign (a regional landmark overlooking Kemerovo in the style of the Hollywood sign, now a cultural icon).

The data demonstrate that even spiritual and religious sphere is not free from the coalmining influence.

\section{Conclusion}

The coal-mining industry is literally part of the regional and cultural environment of Kuzbass notwithstanding the fact that miners make up slightly over $6 \%$ of population. The 
coal culture exerts itself in the natural, urban, social, cultural, linguistic, and academic components, eventually resulting in a complex and multiform cognitive model of the region. The text of culture absorbs regional peculiarities and moulds the population into a unified and homogeneous community with positive attitudes towards the staple industry of the region. The text of culture is largely responsible for the stability and survivability of the mining professions, the sustainability and development of coal mining as such. The text of culture is reported to have manipulative properties because the coal-mining elements pervade the text of culture, demonstrating heroic and romantic perception of the sector and promoting the victorious and glorifying attitudes. The manipulative potential is frequently viewed negatively because the conventional cultural patterns are likely to underestimate ecological, economic, and political issues or distract attention from them.

\section{References}

1. B. Towler, The Future of Energy (Academic Press, London, 2014)

2. N. C. Poudyal, B. R. Gyawali, M. Simon, Journal of Cleaner Production, 217, 530-540 (2019)

3. S. Leinhardt, Social Networks: A Developing Paradigm (Academic Press, London, 2013)

4. I. V. Zykova, Metalanguage of culturology: constants and variants (Gnozis, Moscow, 2017)

5. N. A. Simbirtseva, Human being in the world of Culture, 3, 27-32 (2013)

6. D. Price, Coal Cultures: Picturing Mining Landscapes and Communities (Bloomsbury Visual Arts, Paris, 2018)

7. H. Clinton, What happened (Simon\&Shuister, London, 2017)

8. S. E. Bell, R. York, Rural Sociology 75-1, 111-143 (2010)

9. E. Marinova, N. Rabkina, M. Ryabova, O. Valko, E3S Web Conf., 41, 04040 (2018)

10. J. L. Mickenberg, American girls in Red Russia: chasing the Soviet dream (University of Chicago Press, Chicago, 2017)

11. N. V. Rabkina, Bulletin of Kemerovo State University, 3 :75, 49-56 (2018)

12. V.-M. Lahti Siperia Kutsuu! Kansainvalisen Kuzbas-Siirtokunnan Ja Sen Suomalaisten Tarina 1921-1927 (HDRT, Amsterdam, 2017)

13. W. de. Wagt, J. B. Van Loghem, 1881-1940: Landhuizen, stadswoonhuizen en woningbouwprojecten: beelding van levenshouding. (Haarlem: Schuyt \& Company, Amsterdam ,1995)

14. R. A. Eggink, J. B. van Loghem, Architect van een optimistische generatie, proefschrift. (Technische Universiteit Delft, Delft, 1998)

15. W. T. Smith, The Kuzbass colony, Soviet Russia, 1921-1926. An American contribution to the building of a communist state. (University of Miami, Miami, 1977)

16. T. Schoorl-Straub, Een beetje vrijheid: herinneringen van een Nederlandse vrouw in Siberie. (A.G. Schoonderbeek, Amsterdam, 1965) 